\title{
BMJ Open Subjective symptoms related to GSM radiation from mobile phone base stations: a cross-sectional study
}

\author{
Claudio Gómez-Perretta, ${ }^{1}$ Enrique A Navarro, ${ }^{2}$ Jaume Segura, ${ }^{3}$ Manuel Portolés ${ }^{1}$
}

To cite: Gómez-Perretta C Navarro EA, Segura J, et al. Subjective symptoms related to GSM radiation from mobile phone base stations: a crosssectional study. BMJ Open 2013:3:e003836.

doi:10.1136/bmjopen-2013003836

- Prepublication history for this paper is available online. To view these files please visit the journal online (http://dx.doi.org/10.1136/ bmjopen-2013-003836).

Received 16 August 2013 Revised 16 November 2013 Accepted 20 November 2013

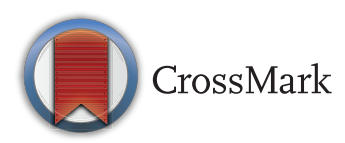

${ }^{1}$ Research Center, University Hospital La Fe, Valencia, Spain

${ }^{2}$ Department of Applied Physics, Universitat de València, Valencia, Spain ${ }^{3}$ Department of Computer Sciences, ETSE-Universitat de València, Valencia, Spain

Correspondence to Professor Enrique A Navarro; enrique.navarro@uv.es

\section{ABSTRACT}

Objectives: We performed a re-analysis of the data from Navarro et al (2003) in which health symptoms related to microwave exposure from mobile phone base stations (BSs) were explored, including data obtained in a retrospective inquiry about fear of exposure from BSs.

Design: Cross-sectional study.

Setting: La Ñora (Murcia), Spain.

Participants: Participants with known illness in 2003 were subsequently disregarded: 88 participants instead of 101 (in 2003) were analysed. Since weather circumstances can influence exposure, we restricted data to measurements made under similar weather conditions.

Outcomes and methods: A statistical method indifferent to the assumption of normality was employed: namely, binary logistic regression for modelling a binary response (eg, suffering fatigue (1) or not (0)), and so exposure was introduced as a predictor variable. This analysis was carried out on a regular basis and bootstrapping (95\% percentile method) was used to provide more accurate Cls.

Results: The symptoms most related to exposure were lack of appetite (OR=1.58, 95\% Cl 1.23 to 2.03); lack of concentration ( $\mathrm{OR}=1.54,95 \% \mathrm{Cl} 1.25$ to 1.89 ); irritability ( $\mathrm{OR}=1.51,95 \% \mathrm{Cl} 1.23$ to 1.85$)$; and trouble sleeping ( $O R=1.49,95 \% \mathrm{Cl} 1.20$ to 1.84). Changes in -2 log likelihood showed similar results. Concerns about the BSs were strongly related with trouble sleeping ( $\mathrm{OR}=3.12,95 \% \mathrm{Cl} 1.10$ to 8.86$)$. The exposure variable remained statistically significant in the multivariate analysis. The bootstrapped values were similar to asymptotic Cls.

Conclusions: This study confirms our preliminary results. We observed that the incidence of most of the symptoms was related to exposure levelsindependently of the demographic variables and some possible risk factors. Concerns about adverse effects from exposure, despite being strongly related with sleep disturbances, do not influence the direct association between exposure and sleep.

The health risk due to exposure to radiofrequency electromagnetic fields (RF EMFs) continues to be discussed today. The study that led to this debate was initiated after verification

\section{Strengths and limitations of this study}

- We used a robust statistical analysis with a highly homogeneous sample in a homogeneous environment.

- A participation bias cannot be ruled out. The late query about concerns (as a possible confounder) may render the results less valid.

- We observed that the incidence of most of the symptoms was related to exposure levels.

that the US embassy in Moscow was being subjected to such radiation from 1953 to May $1975 .{ }^{1}$ Recently, a review of that episode ${ }^{2}$ reopened the debate about the potential harmfulness of RF EMFs. The increasing number of base stations (BSs) on masts and buildings has increased public awareness. This issue has prompted scientific research to establish to what extent low-intensity EMFs may affect the health of humans and other organisms. ${ }^{3} 4$ Furthermore, the term electromagnetic hypersensitivity has been recently introduced in discussions attributing symptoms to exposure to EMFs. ${ }^{5-8}$ A review of this topic ${ }^{9}$ in 2010 found that 8 of the 10 studies evaluated through PubMed had reported increased prevalence of adverse neurobehavioral symptoms or cancer in populations living at distances $<500 \mathrm{~m}$ from BSs.

None of the studies reported exposure above accepted international guidelines, suggesting that current guidelines may be inadequate in protecting health. Thus, the need emerges to revaluate our pioneering work in this field in order to add new procedures and data. Few articles have addressed the possible association between microwave sickness and microwave exposure from Global System for Mobile Communications (GSM) BSs since the publication of our first study. ${ }^{10}$ Chronologically, Santini et $a l^{11}$ and Gadzicka et $a l^{12}$ reported differences in the distancedependent prevalence of symptoms such as headache, impaired concentration and 
irritability. A later Austrian study ${ }^{13}$ showed a positive association between the measured electrical field (GSM 900/ 1800) in bedrooms and headaches, cold hands and feet and difficulties in concentration. An Egyptian study ${ }^{14}$ showed a prevalence of neurological symptoms, such as headache, memory changes, dizziness, tremors, depressive symptoms and sleep disturbances among participants directly exposed to GSM signals from BSs.

The symptoms reported by all the above cited authors belong to those attributed to the microwave syndrome. ${ }^{15}$ However, one article $^{16}$ using personal monitored data from GSM-UMTS frequency bands found no statistical association in adults. More recently, the same authors observed no association in children, ${ }^{17}$ contradictory results in children and adolescents, ${ }^{18}$ and concluded that the few observed significant associations were not causal but rather occurred by chance. Blettner et al ${ }^{19}$ reported in phase 1 of their study more health problems closer to BSs, but in phase $2^{20}$ they concluded that measured EMF emissions were not related to adverse health effects.

Other researchers focused their work on the possible existence of participants with sensitivity to GSM or UMTS signals according to psychological, cognitive or autonomic assessment. These researchers used shortterm exposure (only 30-50 min) under laboratory conditions $^{21-23}$ and revealed a large disparity between participants. Recently, a study measuring several biological stress markers ${ }^{24}$ found that RF EMF emitted by mobile phone BSs from 5.2 to $2126.8 \mu \mathrm{W} / \mathrm{m}^{2}$ increased cortisol and salivary $\alpha$-amylase, while IgA concentration was not significantly modified.

The Selbitz study ${ }^{25}$ in 2010 described a significant dose-response relationship in symptoms related with sleep, mood, joints, infections, skin condition, as well as neurological, cardiovascular, visual and auditory systems and the gastrointestinal tract.

The existence of short-term physiological effects of EMF on sleep quality was not evident in the work of Danker-Hopfe $e t a l^{26}$; however, it was stated that the presence of BSs per se (not the EMF) may have a negative impact on sleep quality.

A Polish study in 2012 did not show a correlation between electrical field strength and frequency of subjective symptoms; however, it showed a correlation between subjective symptoms and the distance to BSs. ${ }^{27}$ A study carried out in Egypt $^{28}$ revealed that exposure to EMF emitted either from mobile phones or BSs had significant effects on the pituitary-adrenal axis. More recently, work developed in $\operatorname{Iran}^{29}$ indicated that symptoms such as nausea, headache, dizziness, irritability, discomfort, nervousness, depression, sleep disturbance, memory loss and lowering of libido were statistically significant in people living near BSs $(<300 \mathrm{~m}$ distances $)$ compared with those living far from the BSs $(>300 \mathrm{~m})$.

In our cross-sectional analysis, ${ }^{10} 11$ of 16 symptoms showed statistically significant higher scores in the group with the maximum exposure level. The symptoms are included in the microwave syndrome. We also reported statistically significant correlation coefficients between the measured electrical field and 14 of 16 symptoms.

A review ${ }^{30}$ recently established several conditions for epidemiological studies to be eligible for introduction in general analysis: eligible studies must quantify exposure using objective measures (such as distance to the nearest BS, spot or personal exposure measurements in a specific frequency range); possible confounders must be considered and the selection of the study population must be clearly free of bias in terms of exposure and outcomes.

Accordingly, in this reanalysis of our previous study, ${ }^{10}$ possible confounders were included in addition to the specific RF EMF measurements made in 2001 (covering the specific range between 900 and $1800 \mathrm{MHz}$ ). Therefore, we coanalysed the effects of other variables such as sociodemographic data and the use of electronic devices. Concern about being damaged by radiation from antennas was also analysed.

The new statistical approach tested the possible influences of other variables, such as demographic data and the use of electronic devices. Moreover, since some concerns have been raised about possible health consequences caused by the emitted microwaves, we analysed whether these symptoms might be related to fear of exposure. As some participants refused to allow measurements in their homes, we analysed whether symptom status or subjective distance to the BS could be a bias of participation in the study. Interestingly, this period was free of other sources of RF such as WIFI or UMTS or the massive use of mobile phones, enabling a specific study of GSM technology. Finally, the suitability of the size of the sample was analysed.

\section{METHODS}

\section{Study design}

We chose a small urban area with mixed rural characteristics: low levels of environmental pollution (more agricultural than industrial); no major differences in socioeconomic characteristics throughout the region (excluding large cities); similar ethnicity (white Caucasian) and language (Spanish) and with mobile phone communication operative for at least 2 years. La Nora was chosen because it had the features of a small city, and was located near the capital (Murcia) in a rural environment without any particular health or environmental problems. Consequently, La Nora was representative of small urban areas in eastern Spain with fewer than 20000 inhabitants-such rural areas accounting for $19.8 \%$ of the population and $35.9 \%$ of the territory in Spain.

Two BS masts, each about $30 \mathrm{~m}$ height, were sited at different positions to provide GSM-900-1800 coverage. The GSM 900 BS was positioned not before 1997 while the GSM 1800 BS was built in December 1999.

Data regarding the main demographic characteristics of the sample and their use of electronic devices was collected through a Spanish-language questionnaire. ${ }^{11}$ All 
of the participants were of the same ethnic origin, shared similar family income levels and general standard of living, and were born in La Nora or nearby. All the residents in the study were living in the village before the erection of both BSs. All of the residents were at home for more than $8 \mathrm{~h}$ a day for at least 6 days a week and normally slept at home.

The core of the questionnaire was a symptom checklist for estimating the frequency of 15 health-related symptoms attributed to microwave sickness. These symptoms were fatigue, irritability, headaches, nausea, loss of appetite, sleep disorders, depressive tendency, dizziness, concentration difficulties, memory loss, skin lesions, visual and hearing deficiencies, walking difficulties and cardiovascular problems. The frequency was quantified as never suffer $=0$, sometimes $=1$, often $=2$ and very often $=3$.

The percentage of residents who reported electrical transformers less than $10 \mathrm{~m}$ from their home was $21.6 \%$, while $42 \%$ reported high-voltage power lines less than $100 \mathrm{~m}$ from home. Finally, $40 \%$ of residents reported a TV transmitter within a radius of around $4 \mathrm{~km}$.

The questionnaire included a statement that its purpose was health research and that the data gathered would be confidential.

Some 215 questionnaires were randomly distributed through 17 streets representing practically the entire village. The houses were selected using a street map of the village. In total, 150 questionnaires were collected with the remainder being uncollected because nobody was at home (31) or there was a refusal by the householder to complete the questionnaire (34).

During 2001, 101 RF EMF measurements in bedrooms were made. The other (49) residents who refused admittance for taking the measurements (16) were not at home for the scheduled measurement appointment (10) or had serious health problems (23).

However, some changes are now being introduced in this reanalysis. Thirteen of the participants included in the original study have now been eliminated: 2 participants were eliminated (one regarding alcohol abuse and another regarding pregnancy) to increase the requirement on health criteria and 11 participants were eliminated to increase the homogeneity of the RF EMFs measurements because there was a change (it was raining) in the usual dry weather conditions when the respective broadband measurements were registered.

The reanalysis of the dataset, which is the main focus of this paper, was finally performed with 88 participants (45 women and 43 men) instead of the 101 analysed in 2001.

\section{Concerns about microwave exposure}

Sixty-six of the 88 participants were reached by telephone in February 2012 and asked two questions:
A. Were you worried about the masts (BSs) when they were erected?
B. Did you believe their radiation (BSs) could damage your health?

In all cases, those who were worried about the masts were concerned about health consequences. Twentyseven participants (40.9\%) responded 'no' and 39 $(59.1 \%)$ responded 'yes'. Responses were analysed relative to age (analysis of variance (ANOVA) test), sex ( $\lambda$ statistic) and subjective distance to BS (Somers' D statistic).

\section{Exposure assessment}

Broadband measurements were made on two Saturdays in February and March 2001 from 11:00 to 19:00 with a portable electrical field (400 MHz-3 GHz) detector (Nuova Elettronica Model LX-1435). This meter was calibrated with an HP-8510C network analyser inside an anechoic chamber at the University of Valencia. During the bedroom exposure assessment, the electric field probe was held for approximately $5 \mathrm{~min}$ about $1 \mathrm{~m}$ from the walls and $1.2 \mathrm{~m}$ above the ground-and moved around a circle of $0.25 \mathrm{~m}$ radius, orientating the antenna in different directions to obtain the maximum electrical field strength above the bed.

To check the intensity of TV and radio channels, as well as the intensity of working channels and broadcast channels for the GSM-900-1800 BSs, measurements of the spectral power density were carried out with a probe antenna and a portable spectrum analyser.

The probe was mounted on a linen phenolic tripod $1.2 \mathrm{~m}$ above the ground. The position of the probe was the same on both days - on a hill next to the village and $20 \mathrm{~m}$ from the BS. With the spectrum analyser we scanned the frequency bands and the levels were averaged for $6 \mathrm{~min}$. The measurement of the spectrum was similar on both days-with a difference in the peak estimation (channel carriers) of about $1 \mathrm{~dB}$.

The measured broadband exposure was almost invariable during the time interval of the measurements. Exposure changed with the position or place but it did not change over time, and this could be related with a low intensity of traffic (few phone calls) and the high and constant intensity of the broadcast channel. ${ }^{10}$

\section{Statistical analysis}

Demographic data were analysed using the Mann-Whitney one-way ANOVA and $\chi^{2}$ test. Differences between groups were performed through variance (ANOVA) and covariance analysis.

The main statistical analysis was made using binary logistic regression (mode enter) carried out on a regular basis with subsequent bootstrapping (1000 bootstrap replications, $95 \%$ percentile method and simple sampling $)^{31}$ to provide more accurate SE and CIs. After producing (1000) bootstrap replicates $\theta \mathrm{b}$ of an estimator $\theta$, the bootstrap SE was the SD of the bootstrap replicates.

$$
\begin{gathered}
\operatorname{SE}(\theta)=\sqrt{ }\left[\sum(\theta b-\theta)^{2} /(r-1)\right] \\
b=1 \rightarrow r
\end{gathered}
$$


where $\theta$ is the mean of the $\theta b$. Owing to our small sample size, a non-parametric CI for the estimate (mean) was constructed from the quartiles of the bootstrap sampling distribution of $\theta$. The $95 \%$ percentile interval $(\theta$ (lower) $<\theta<\theta$ (upper)) is shown, where $\theta b$ are the r-ordered bootstrap replicates: lower $=0.025 \times \mathrm{r}$ (sample 25) and upper $=0.975 \times$ r (sample 975$)$.

The dependent variables (health-related symptoms) given in four ordinal categories $(0=$ never, $1=$ sometimes, $2=$ often and $3=$ very often $)$ were dichotomised $(0,1=0$ vs 2, $3=1)$.

The 15 health-related symptoms described above constituted the dichotomous dependent variables. Univariate analysis was then performed for each symptom and for each of the predictor variables: exposure to $\mathrm{BS}\left(\mu \mathrm{W} / \mathrm{m}^{2}\right.$ as a natural logarithmic) and age were used as continuous variables, while gender, computer use $>2 \mathrm{~h} /$ day, mobile phone use $>20 \mathrm{~min} /$ day and worry about the antennae were used as dichotomous variables. The covariates with predictive value were considered for the multivariate analysis. Thus possible confounder effects were evaluated.

In all cases, changes in -2 log likelihood, OR, 95\% CIs and the $p$ value were calculated. For all tests, a $p$ value below 0.05 was considered statistically significant.

We used the GSM exposure (the measurement of RF EMF in the bedroom) as a continuous variable because it is recognised that categorisation of continuous variables introduces major problems in the analysis and interpretation of models derived in a data-dependent fashion. ${ }^{32-34}$

We chose exposure values in the logarithmic form because these values are well grouped around their median, while the raw values showed a high dispersion of values, with 2 outliers and 10 extreme values (data not shown).

Confounding was assessed by adding the potentially confounding variable to the model and making a subjective decision as to whether or not the coefficient of the variable of interest, ORs of GSM exposure, had changed substantially. A $10 \%$ variation was accepted as a considerable change.

Possible interactions between covariates were also evaluated.

The maximum number of covariates included in each multivariate analysis was calculated following this formula. $^{35}$ Let $\pi$ be the smallest of the proportions of negative or positive cases in the population and $\mathrm{k}$ the number of covariates, then the minimum number of cases to include is:

$$
\mathrm{N}=10 \mathrm{k} / \pi
$$

Goodness-of-fit tests such as the classification table, the Hosmer-Lemeshow statistic, receiver operating characteristic (ROC) curves, Cox and Snell's and Nagelkerke's Pseudo $\mathrm{R}^{2}$ measures were used. The Wald statistic was also evaluated to test the significance of individual independent variables. Moreover, possible multicollinearity was also tested.

With the predicted probability scores derived from the regression analysis, ROC curves were constructed for all symptoms or modalities in order to analyse sensitivity and specificity levels. For each curve, the best cut-offs for GSM exposure that maximises (sensitivity+specificity) were also calculated.

For statistical analysis, we used the Statistical Package for Social Sciences, V.21.0 (IBM SPSS Inc, Chicago, Illinois, USA) for Windows.

Owing to an exposure assessment for transformers, high-voltage power lines and radio or TV transmitters based on self-estimated distances would not produce a reliable exposure estimate, it was decided to omit these covariates in the analysis.

\section{RESULTS}

Demographic data and the percentage of users of personal computers and mobile phones were analysed. The mean age was 42 and 17 years $(\mathrm{SD} \pm 17.61$, interval $15-81$ ). Women totalled $51.1 \%$ (mean age $=45.08$ years, $\mathrm{SD}=17.98$; interval $=15-81$ ) and $48.9 \%$ were men (mean age $=39.12$ years, $\mathrm{SD}=16.88$; interval $=15-75)$. A total of $13.6 \%$ participants regularly used computers and $23.9 \%$ used mobile phones.

No differences related with age and use of mobile phones or computers were found between the sexes.

The univariate logistic regression indicated that age was inversely associated with irritability ( $\mathrm{OR}=0.97,95 \%$ CI 0.95 to 0.99 ) and that the oldest had the greatest difficulties hearing $(\mathrm{OR}=1.03,95 \%$ CI 1.01 to 1.06$)$ and walking $(\mathrm{OR}=1.04,95 \%$ CI 1.01 to 1.07$)$. However, gender clearly did not influence the outcome of any dependent variable. Use of mobile phones was linked with lack of appetite and vertigo, while worry about the radiation from BSs was associated with trouble sleeping (table 1). However, concern about radiation from BSs was unrelated to age (ANOVA test), sex ( $\lambda$ statistic) or subjective distance to BS (Somers' D statistic).

Most of the symptoms were related with GSM exposure, especially fatigue, irritability, lack of appetite, trouble sleeping, depression and lack of concentration. Change in -2 log likelihood showed similar results (table 2). Figure 1 shows the distribution of EMF measurements throughout the sample.

ROC curves for each of the logistic regression models (GSM exposure vs each symptom) oscillated between 0.65 and 0.87 (table 3). Headaches (0.84), nausea (0.86), appetite (0.87) and vascular problems (0.85) showed the highest values, while memory (0.67), skin (0.67) and visual disturbances (0.65) showed the lowest values. The Hosmer and Lemeshow test indicated that most analyses showed no significant $\mathrm{p}$ values. The exceptions were fatigue $(0.003)$, depression $(0.003)$ and vertigo $(0.03)$. In the majority of the cases, the models predicted better specificity than sensitivity. Only in the 
Table 1 Univariate ORs and 95\% Cls of all clinical symptoms related with various possible confounders

\begin{tabular}{|c|c|c|c|c|c|c|}
\hline \multirow{3}{*}{$\begin{array}{l}\text { Symptom/variable } \\
\text { Fatigue }\end{array}$} & \multirow{2}{*}{\multicolumn{2}{|c|}{$\begin{array}{l}\text { Worry about BSs (1) } \\
\text { OR (95\% Cl) }\end{array}$}} & \multirow{2}{*}{\multicolumn{2}{|c|}{$\begin{array}{l}\text { Computer use (2) } \\
\text { OR }(95 \% \mathrm{Cl})\end{array}$}} & \multirow{2}{*}{\multicolumn{2}{|c|}{$\begin{array}{l}\text { Mobile use (3) } \\
\text { OR }(95 \% \mathrm{CI})\end{array}$}} \\
\hline & & & & & & \\
\hline & 0.67 & 0.23 to 1.90 & 2.62 & 0.76 to 9.04 & 1.56 & 0.56 to 4.35 \\
\hline Irritability & 1.13 & 0.43 to 3.03 & 1.56 & 0.45 to 5.34 & 2.62 & 0.94 to 7.33 \\
\hline Headaches & 1.75 & 0.62 to 4.94 & 1.39 & 0.34 to 5.58 & 1.56 & 0.51 to 4.83 \\
\hline Nausea & 0.68 & 0.18 to 2.24 & 0.34 & 0.04 to 2.84 & 1.43 & 0.44 to 4.67 \\
\hline Lack of appetite & 1.05 & 0.33 to 3.40 & 3.16 & 0.87 to 11.44 & $4.28^{\star \star}$ & 1.43 to 12.78 \\
\hline Trouble sleeping & $3.12^{*}$ & 1.10 to 8.86 & 0.55 & 0.16 to 1.88 & 0.74 & 0.27 to 2.02 \\
\hline Depression & 1.06 & 0.39 to 2.93 & 0.81 & 0.22 to 2.93 & 1.03 & 0.38 to 2.84 \\
\hline Lack of concentration & 0.92 & 0.35 to 2.47 & 1.11 & 0.33 to 3.76 & 2.79 & 0.99 to 7.80 \\
\hline Memory loss & 1.71 & 0.62 to 4.75 & 0.41 & 0.10 to 1.64 & 1.35 & 0.50 to 3.61 \\
\hline Skin alterations & 0.74 & 0.23 to 2.35 & $\phi$ & $\phi$ & 0.63 & 0.16 to 2.45 \\
\hline Visual disturbances & 1.31 & 0.48 to 3.60 & 0.77 & 0.21 to 2.77 & 1.63 & 0.60 to 4.39 \\
\hline Vertigo & 0.61 & 0.20 to 1.91 & 0.77 & 0.19 to 3.10 & $2.90^{*}$ & 1.04 to 8.07 \\
\hline Vascular alteration & 0.96 & 0.27 to 3.43 & 1.48 & 0.35 to 6.17 & 2.04 & 0.65 to 6.41 \\
\hline Hearing problems & 0.59 & 0.20 to 1.70 & 0.77 & 0.19 to 3.10 & 0.48 & 0.15 to 1.60 \\
\hline Walking difficulty & 0.60 & 0.20 to 1.79 & $\phi$ & $\phi$ & 0.42 & 0.11 to 1.60 \\
\hline
\end{tabular}

${ }^{*} p<0.05 ;{ }^{* *} p<0.01$

(1) Not worried, as reference codes. (2) and (3) no device use, as reference code, $\phi$ any participant affected using computer.

BS, base station.

case of headaches and sleep disorder, did sensitivity prevail over specificity (table 3-classification table). In the extreme case, skin and vascular problems showed null or minimum sensitivity and $100 \%$ specificity. Nagelkerke pseudo $\mathrm{R}^{2}$ showed acceptable coefficients with the exception of the symptoms related with vertigo and skin problems (table 3 ).

Threshold cut-off values of GSM for sleep, attention, irritability and memory are also shown (table 3). The remaining cut-off values were not considered since sensitivity or specificity was reported at below $0.50 \%$.
The influence of other covariates on the GSM ORs coefficients, such as age, cellular use and concern about the BS, was always less than $10 \%$ (table 2).

There was no observed multicollinearity among variables. The $\kappa$ values according to factor analysis were always lower than 2 and well below the critical value of 30 .

Finally, no interactions between covariates were observed.

SEs and CIs obtained by resampling were similar to those calculated from the asymptotic approximation (table 4). There was a small bias or difference between

Table 2 ORs and 95\% Cls for GSM exposure: increase in risk per increase in log GSM $\left(\mu \mathrm{W} / \mathrm{m}^{2}\right)$

\begin{tabular}{|c|c|c|c|}
\hline Symptom & OR $(95 \% \mathrm{Cl})$ & Change in -2 log likelihood & OR $(95 \% \mathrm{Cl})$ \\
\hline Fatigue & $1.39^{\star \star \star}(1.14$ to 1.70$)$ & $11.74^{\star * \star}$ & $2.13^{\star \star \star}(1.34$ to 3.83$)$ \\
\hline Irritability & $1.51^{\star \star *}(1.23$ to 1.85$)$ & $19.36^{\star \star \star}$ & $2.58^{* * *}$ (1.61 to 4.12$)$ \\
\hline Irritability (adjusted with age) & $1.47^{\star * *}(1.20$ to 1.81$)$ & - & $2.44^{\star * *}(1.52$ to 3.94$)$ \\
\hline Headaches & $1.43^{\star \star}(1.15$ to 1.78$)$ & $12.32^{\star \star \star}$ & $2.28^{\star \star}(1.37$ to 3.78$)$ \\
\hline Nausea & $1.38^{\star *}(1.09$ to 1.73$)$ & $8.3^{\star \star}$ & $2.09^{\star *}(1.23$ to 3.55$)$ \\
\hline Lack of appetite & $1.58^{\star \star}(1.23$ to 2.03$)$ & $16.31^{\star \star *}$ & $2.86^{\star * *}(1.60$ to 5.09$)$ \\
\hline Lack of appetite (adjusted to cellular use) & $1.53^{\star *}(1.19$ to 1.99$)$ & - & $2.68^{\star \star \star}(1.48$ to 4.84$)$ \\
\hline Trouble sleeping & $1.49^{\star * \star}(1.20$ to 1.84$)$ & $16.38^{\star \star \star}$ & $2.49^{\star \star \star}(1.52$ to 4.08$)$ \\
\hline Trouble sleeping (adjusted to worry to BSs) & $1.64^{* * *}(1.22$ to 2.19$)$ & - & $3.11^{\star * *}$ (1.59 to 6.09$)$ \\
\hline Depression & $1.41^{* * *}(1.16$ to 1.72$)$ & $13.99^{\star \star *}$ & $2.22^{\star \star \star}(1.42$ to 3.48$)$ \\
\hline Concentration & $1.54^{\star * *}(1.25$ to 1.89$)$ & $20.75^{\star \star \star}$ & $2.68^{\star \star *}$ (1.67 to 4.32$)$ \\
\hline Memory & $1.27^{\star *}(1.06$ to 1.52$)$ & $7.29^{\star *}$ & $1.73^{\star \star}(1.14$ to 2.60$)$ \\
\hline Skin & $1.24^{*}(1.001$ to 1.54$)$ & $4.08^{*}$ & $1.65^{*}(1.01$ to 2.71$)$ \\
\hline Visual & $1.23 *(1.03$ to 1.46$)$ & $5.30^{*}$ & $1.59 *(1.06$ to 2.40$)$ \\
\hline Vertigo & $1.36^{\star *}(1.11$ to 1.66$)$ & $10.14^{\star \star \star}$ & $2.02^{\star *}(1.28$ to 3.20$)$ \\
\hline Vertigo (adjusted to cellular use) & $1.32^{\star *}$ (1.08 to 1.62$)$ & - & $1.91^{\star *}(1.20$ to 3.04$)$ \\
\hline Vascular & $1.32^{*}(1.05$ to 1.64$)$ & $6.30^{*}$ & $1.88^{*}(1.12$ to 3.14$)$ \\
\hline Hearing & $0.96(0.80$ to 1.15$)$ & & 0.90 (0.59 to 1.37$)$ \\
\hline Walking & $0.95(0.78$ to 1.15$)$ & & $0.88(0.57$ to 1.37$)$ \\
\hline
\end{tabular}




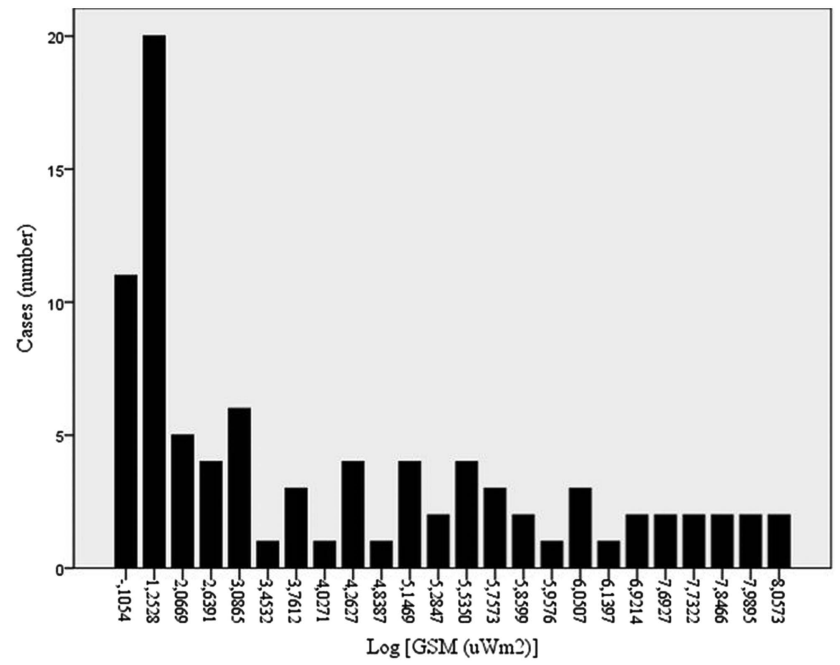

Figure 1 Distribution of electromagnetic field (EMF) measurement throughout the sample.

the average bootstrap coefficients (not shown) and the respective estimates obtained from the original sample.

There were no global health differences between those who permitted a bedroom exposure measurement (88 in our previous model) and those who refused RF measurements (26), and these results were unaltered when using age as a covariate. Square partial eta measured a $0 \%$ contribution of the willing participation variable to symptoms, such as irritability, headaches, walking difficulties and hearing loss that correlated with age. There was no relationship between subjective distance to the BS and willingness to participate (Pearson $\chi^{2}=2.80$, $\mathrm{df}=1 ; \mathrm{p}=0.094)$.

However, ANOVA showed that the group with recorded RF EMF levels was more prone to symptoms of memory loss $(\mathrm{F}=5.07 ; \mathrm{p}=0.027)$, while participants without EMF measures showed more skin problems $(\mathrm{F}=10.66 ; \mathrm{p}=0.001)$.

\section{DISCUSSION}

In the present reanalysis, a more robust statistical method was employed that was indifferent to the assumption of normality. To reduce the limitation of the sample size effect and extrapolate our results to the entire population from which the sample was obtained, a resample method or bootstrapping was used.

This new study partially confirms our preliminary results-namely, that most of the symptoms are related to GSM levels independent of the demographical variables and some possible risk factors. Related to microwave radiation, the spectral power density analysis maintained that the most important contribution to broadband measurements was from GSM 900/1800, and the main variability of the measurements between different places was due to a different coverage of the GSM $900 / 1800$ signals, that is, spatial variability. This was further supported by the fact that the antenna used was fairly insensitive to frequencies below $400 \mathrm{MHz}$. Therefore, the radio channels $80-110 \mathrm{MHz}$ were not a significant part of the broadband measurements. Moreover, the narrow band measurements showed TV channels with substantially lower intensities than the GSM 900/1800 signals. The effects from these exposures will therefore not confound the effects of BSs. Moreover, some authors ${ }^{13}$ found that the only relevant contribution to the variance of the high microwave exposure was from BSs-up to $93 \%$ of variance. Moreover, at the time of our study, the GSM signal was almost invariable in time because there were very few calls. The main contribution was made from the broadcast channels working almost constantly throughout the day. Short-range evaluations of exposure could be acceptable for describing a $24 \mathrm{~h}$ period and the measurements were made in bedrooms-a location where the participants were assumed to spend significant periods of time.

However, some participants were mobile phone users at the time of this study and exposure to a mobile

Table 3 Goodness-of-fit of the outcome binary response variable related to GSM exposure (log=In)

\begin{tabular}{|c|c|c|c|c|c|c|c|}
\hline \multirow[b]{2}{*}{ Symptom } & \multirow{2}{*}{$\begin{array}{l}\text { ROC curves } \\
\text { area }\end{array}$} & \multicolumn{3}{|c|}{ Classification table } & \multirow[b]{2}{*}{ Pseudo- $^{\star \star 2}$ (1) } & \multirow{2}{*}{$\begin{array}{l}\text { Cut-off (2) } \\
\text { (log GSM) }\end{array}$} & \multirow{2}{*}{$\begin{array}{l}\text { Cut-off (2) } \\
\text { GSM }\left(\mu \mathrm{W} / \mathrm{m}^{2}\right)\end{array}$} \\
\hline & & SSV & SPF & AV & & & \\
\hline Headaches & $0.84^{\star \star \star}$ & 0.90 & 0.23 & 0.72 & 0.41 & - & 1.77 \\
\hline Sleep & $0.78^{\star \star \star}$ & 0.82 & 0.66 & 0.76 & 0.28 & 1.66 & 5.26 \\
\hline Attention & $0.78^{\star \star \star}$ & 0.67 & 0.72 & 0.69 & 0.28 & 3.61 & 36.97 \\
\hline Irritability & $0.76^{\star \star \star}$ & 0.67 & 0.73 & 0.71 & 0.26 & 3.61 & 36.97 \\
\hline Memory & $0.67^{\star \star}$ & 0.54 & 0.77 & 0.67 & 0.11 & 4.99 & 146.94 \\
\hline Depression & $0.75^{\star \star \star}$ & 0.46 & 0.76 & 0.65 & 0.20 & - & 184.93 \\
\hline Visual & $0.65^{\star}$ & 0.24 & 0.83 & 0.60 & 0.08 & - & 368.71 \\
\hline Fatigue & $0.73^{\star \star \star}$ & 0.22 & 0.90 & 0.69 & 0.18 & - & 685.4 \\
\hline Vertigo & $0.74^{\star \star \star}$ & 0.16 & 0.87 & 0.67 & 0.19 & - & 685.4 \\
\hline Appetite & $0.87^{\star \star \star}$ & 0.40 & 0.94 & 0.85 & 0.43 & - & 1495.18 \\
\hline Nausea & $0.86^{\star \star \star}$ & 0.46 & 0.93 & 0.87 & 0.38 & - & 1495.18 \\
\hline Vascular & $0.85^{\star \star \star}$ & 0.20 & 1.0 & 0.90 & 0.34 & - & 3041.18 \\
\hline Skin & $0.67^{*}$ & 0.00 & 1.00 & 0.81 & 0.072 & - & 8604.15 \\
\hline
\end{tabular}

Cut-off values of exposure to microwaves according to ROC analysis. The data are presented in the ascending order.

${ }^{*} p<0.05 ;{ }^{* *} p<0.01 ;{ }^{* * *} p<0.001$ (1) Nagelkerke (2) cut-off (ROC curve): only values showing SSV and SPF above 0.5 are reported.

AV, average; GSM, Global System for Mobile Communication; ROC, receiver operating characteristic; SPF, specificity; SSV, sensitivity. 
Table 4 Statistics for $r=1000$ bootstrapped binary logistic regression (GSM exposure coefficients: increase in risk per increase in log GSM $\left(\mu \mathrm{W} / \mathrm{m}^{2}\right)$

\begin{tabular}{|c|c|c|c|c|c|c|c|c|}
\hline \multirow[b]{3}{*}{ Symptom } & \multirow[b]{3}{*}{$\mathbf{B}^{*}$} & \multicolumn{4}{|c|}{ Bootstrap } & \multicolumn{3}{|c|}{ Normal } \\
\hline & & \multirow[b]{2}{*}{ Bias } & \multirow[b]{2}{*}{ SE } & \multicolumn{2}{|c|}{$\begin{array}{l}95 \% \text { percentile } \\
\text { intervals }\end{array}$} & \multirow[b]{2}{*}{ SE } & \multicolumn{2}{|l|}{$95 \% \mathrm{Cl}$} \\
\hline & & & & Lower & Upper & & Lower & Upper \\
\hline Fatigue & 0.329 & 0.012 & 0.097 & 0.155 & 0.539 & 0.102 & 0.128 & 0.529 \\
\hline Irritability & 0.411 & 0.016 & 0.110 & 0.241 & 0.670 & 0.104 & 0.207 & 0.615 \\
\hline Headache & 0.358 & 0.022 & 0.139 & 0.149 & 0.688 & 0.113 & 0.137 & 0.578 \\
\hline Nausea & 0.319 & 0.013 & 0.124 & 0.099 & 0.590 & 0.118 & 0.088 & 0.550 \\
\hline Appetite & 0.456 & 0.026 & 0.134 & 0.264 & 0.784 & 0.128 & 0.205 & 0.707 \\
\hline Sleep & 0.396 & 0.022 & 0.124 & 0.193 & 0.690 & 0.109 & 0.181 & 0.610 \\
\hline Depression & 0.346 & 0.012 & 0.102 & 0.174 & 0.583 & 0.100 & 0.151 & 0.541 \\
\hline Attention & 0.429 & 0.020 & 0.118 & 0.254 & 0.711 & 0.106 & 0.222 & 0.636 \\
\hline Memory & 0.237 & 0.009 & 0.098 & 0.057 & 0.448 & 0.091 & 0.058 & 0.415 \\
\hline Skin & 0.217 & 0.008 & 0.110 & 0.011 & 0.451 & 0.110 & 0.001 & 0.433 \\
\hline Visual & 0.203 & 0.004 & 0.093 & 0.037 & 0.398 & 0.090 & 0.026 & 0.379 \\
\hline Hearing & -0.05 & -0.002 & 0.089 & -0.219 & 0.143 & 0.093 & -0.228 & 0.135 \\
\hline Vertigo & 0.306 & 0.010 & 0.101 & 0.127 & 0.530 & 0.102 & 0.107 & 0.505 \\
\hline Walking & -0.05 & -0.006 & 0.098 & -0.265 & 0.120 & 0.098 & -0.246 & 0.138 \\
\hline Vascular & 0.274 & 0.010 & 0.109 & 0.084 & 0.520 & 0.114 & 0.051 & 0.497 \\
\hline
\end{tabular}

Asymptotic SEs and $95 \% \mathrm{Cls}$ are also shown for comparison.

${ }^{*} \beta$ coefficient (log OR).

GSM, Global System for Mobile Communication.

phone during a phone call is much higher than that received from BSs. Nevertheless, some authors ${ }^{13}$ stated about that there is no a priori argument why these lower levels should have no effect on the presence of a widespread use of mobile telephones. Exposure to a BS will be at a low but almost constant level for many hours of the day and especially at night.

While GSM exposure was associated with most of the symptoms, walking difficulties and hearing loss were correlated only with age. Age also remained slightly inversely associated with irritability. Users of cellular phones were more prone to symptoms of loss of appetite and vertigo, while those who expressed worry about the BSs were associated with sleep problems. This later finding was in concordance with two other articles. ${ }^{13} 2026$ However, worry about the BSs was unrelated with age, gender or subjective distance to BSs. This agrees with an article ${ }^{36}$ claiming that there was no statistically significant association between symptom occurrence associated with perceived proximity to BSs, psychological components, sociodemographic characteristics and distance to BSs or power lines.

Some authors indicated that opponents of mobile phone towers generally do not express anxieties about EMF exposure, indicating that the risk rating is comparable with other commonly perceived hazards in the modern world. ${ }^{37}$

None of the analysed covariates behaved as confounders. The relationship of GSM exposure with irritability, sleep troubles, lack of appetite and vertigo remained statistically significant despite the introduction of the above covariates.
When the conventional multivariate analysis was tested using bootstrapping it was observed that the SE and CIs obtained by resampling were similar to those calculated from asymptotic approximation and this supports the adequacy of our conventional analysis. Our sample, chosen at random, represents the population from which it came.

The model appeared generally well adjusted while the cut-off values could constitute good guidance for predicting the threshold of symptom appearance.

We cannot truly state that residents were more worried, equally worried or less worried than elsewhere in this region, since we cannot provide the percentage of those worried about the BS masts in La Nora compared with other nearby places. However, information about this issue was widespread in this region at the time, and the circumstances at La Nora were shared with most other small urban and rural areas. The sample was randomly selected but a participation bias cannot be ruled out since most of our participants expressed fear regarding BSs and this could contribute to their participation in the study. It is also possible to speculate that the percentage of participants who refused to participate did so for the opposite reasons (indifference about BSs). In this regard, neither health status nor subjective distance to the BS explained a willingness to participate in the study.

Concerns about radiation from BSs were not related to age, sex or subjective distance to BSs. This agrees with statements from several authors ${ }^{13}$ that living near a BS does not make people generally fearful, but people who generally worry about fields express stronger fears when they live close to a station. 
Nevertheless, irrespective of these explanations, there seems to be effects of exposure that occur independently of the fear felt by the participants, since controlling for fear did not change the association between exposure and symptoms. However, the late query about concerns (as a possible confounder) may render the results less valid. In contrast to our findings, note that biological grounds explaining non-thermal effects have not been clearly established. Recently, it has been stated that voltage-gated calcium channels are essential to the beneficial or adverse responses to microwave EMFs, nanosecond EMF pulses and static electrical and magnetic fields. ${ }^{38}$

In summary, the results of this study indicate that effects of very low but long-lasting exposure to emissions from mobile telephone BSs on well-being cannot be ruled out. The effects almost completely matched the symptoms described within the microwave syndrome. Finally, unravelling the causal pathways would be best performed with an experimental study design.

\section{CONCLUSIONS}

This new study partially confirms our preliminary results about microwave sickness resulting from exposure to emissions from GSM mobile phone BSs. Fatigue, irritability, lack of appetite, sleep troubles, depression and lack of concentration were especially related with GSM exposure.

These results were independent of the main sociodemographic variables, other EMF exposures and anxiety about being irradiated. Nevertheless, we confirm that apprehension about modern technology could predict some symptoms, especially those related with sleep problems.

Our results agree with those who claimed that by distorting perceptions of risk, disproportionate precaution might paradoxically lead to illness that would not otherwise occur. ${ }^{39}$ However, health changes related with GSM exposure seem to occur in a manner unrelated with those fears. Finally, exposure was very low during the period and also very low in comparison with Spanish recommendations ${ }^{40}$ and international guidelines. ${ }^{41}$

\section{Recommendations}

We subscribe to the guidelines observed by other authors ${ }^{42}$ in following the principle of prevention while the non-thermal effects are not considered in any official standard. This includes exposure minimisation within the limits of technical feasibility to guarantee a significant reduction in long-term radiation exposure to cellular phone towers in residential areas. Epidemiological and clinical studies should continue to observe possible health changes in the population. Finally, clear information about the correct use of newer electronic devices should be implemented.

Acknowledgements The authors would like to express their gratitude to Angeles Martinez Gomez for her assistance during the fieldwork in La Ñora as well as to the Spanish Ministry of Science and Technology.
Contributors CG-P was mainly responsible for designing and writing the manuscript and also made the main statistical contribution. EAN was one of the researchers responsible for the design and acquisition of radiofrequency electromagnetic field (RF EMF) data, as well as writing and reviewing the manuscript. JS contributed mainly in processing the RF EMF data, while MP was responsible for the design and final review of the manuscript.

Funding This work was funded by the Spanish Ministry of Science and Technology for grant FIT number 070000-2002-58.

Competing interests None.

Patient consent Obtained.

Ethics approval Ethical Committee of the University of Valencia in accordance with the Declaration of Helsinki (http://www.wma.net/e/policy/b3.htm)

Provenance and peer review Not commissioned; externally peer reviewed.

Data sharing statement The data used in this statistical analysis can be obtained from Dr CG-P on request by email (gomez_cla@gva.es).

Open Access This is an Open Access article distributed in accordance with the Creative Commons Attribution Non Commercial (CC BY-NC 3.0) license, which permits others to distribute, remix, adapt, build upon this work noncommercially, and license their derivative works on different terms, provided the original work is properly cited and the use is non-commercial. See: http:// creativecommons.org/licenses/by-nc/3.0/

\section{REFERENCES}

1. Lilienfeld AM, Tonascia J, Tonascia S, et al. Foreign service health status study, evaluation of health status of foreign service and other employees from selected Eastern European posts. Baltimore: Dept Epidemiology, School of Hygiene and Public Health, the Johns Hopkins University, 1978.

2. Elwood JM. Microwaves in the cold war: the Moscow embassy study and its interpretation. Review of a retrospective cohort study. Environ Health 2012;11:8.

3. Belyaev IY. Non-thermal biological effects of microwaves. Microw Rev 2005a;11:13-29.

4. Belyaev IY. Non-thermal biological effects of microwaves: current knowledge, further perspective, and urgent needs. Electromagn Biol Med 2005b;24:375-403.

5. Röösli M, Moser M, Baldinini Y, et al. Symptoms of ill health ascribed to electromagnetic field exposure-a questionnaire survey. Int J Hyg Environ Health 2004;207:141-50.

6. Frick U, Mayer M, Hauser S, et al. Entwicklung eines deutschprachigen Messinsntrumentes für "ElektrosmogBeschwerden". Umwelt Med Forsch Prax 2006;11:103-13.

7. Eltiti S, Wallace D, Ridgewell A, et al. Does short-term exposure to mobile phone base station signals increase symptoms in individuals who report sensitivity to electromagnetic fields? A double-blind randomised provocation study. Environ Health Perspect 2007;115:1603-8.

8. Eltiti S, Wallace D, Ridgewell A, et al. Short-term exposure to mobile phone base station signals does not affect cognitive functioning or physiological measures in individuals who report sensitivity to electromagnetic fields and controls. Bioelectromagnetics 2009;30:556-63.

9. Khurana VG, Hardell L, Everaert J, et al. Epidemiological evidence for a health risk from mobile phone base stations. Int J Occup Environ Health 2010;16:263-7.

10. Navarro EA, Segura J, Portolés $M$, et al. The microwave syndrome: a preliminary study in Spain. Electromagn Biol Med 2003;22:161-9.

11. Santini R, Santini $P$, Danze J, et al. Study of the health of people living in the vicinity of mobile phone base stations: I. influences of distance and sex. Pathol Biol 2002;50:369-73.

12. Gadzicka E, Bortkiewicz A, Zmyslony M, et al. Assessment of subjective complaints reported by people living near mobile phone base stations [Abstract]. Biuletyn PTZE Warsaw 2006;14:23-6.

13. Hutter $H$, Moshammer $H$, Wallner $P$, et al. Subjective symptoms, sleeping problems, and cognitive performance in subjects living near mobile phone base stations. Occup Environ Med 2006;63:307-13.

14. Abdel-Rassoul G, El-Fateh OA, Salem MA, et al. Neurobehavioral effects among inhabitants around mobile phone base stations. Neurotoxicology 2007;28:434-40. 
15. Johnson-Liakouris AG. Radiofrequency (RF) Sickness in the Lilienfeld Study: an effect of modulated microwaves? Arch Environ Health 1998;53:236-8.

16. Thomas $\mathrm{S}$, Kühnlein $\mathrm{A}$, Heinrich $\mathrm{S}$, et al. Personal exposure to mobile phone frequencies and well-being in adults: a cross-sectional study based on dosimetry. Bioelectromagnetics 2008;29:463-70.

17. Kühnlein $\mathrm{A}$, Heumann $\mathrm{C}$, Thomas $\mathrm{S}$, et al. Personal exposure to mobile communication networks and well-being in children-a statistical analysis based on a functional approach.

Bioelectromagnetics 2009;30:261-9.

18. Heinrich S, Thomas S, Heumann C, et al. Association between exposure to radiofrequency electromagnetic fields assessed by dosimetry and acute symptoms in children and adolescents: a population based cross-sectional study. Environ Health 2010;9:75.

19. Blettner M, Schlehofer B, Breckenkamp J, et al. Mobile phone base stations and adverse health effects: phase 1 of a population-based, cross-sectional study in Germany. Occup Environ Med 2009;66:118-23.

20. Berg-Beckhoff G, Blettner M, Kowall B, et al. Mobile phone base stations and adverse health effects: phase 2 of a cross-sectional study with measured radio frequency electromagnetic fields. Occup Environ Med 2009;66:124-30.

21. Augner $\mathrm{C}$, Florian M, Pauser $\mathrm{G}$, et al. GSM base stations: short-term effects on well-being. Bioelectromagnetics 2009;30:73-80.

22. Furubayashi $\mathrm{T}$, Ushiyama $\mathrm{A}$, Terao $\mathrm{Y}$, et al. Effects of short-term W-CDMA mobile phone base station exposure on women with or without mobile phone related symptoms. Bioelectromagnetics 2009;30:100-13.

23. Zwamborn AP, Vossen SH, van Leersum BJ. Effects of global communication system radio-frequency fields on well being and cognitive functions of human subjects with and without subjective complaints. Netherlands Organ Appl Sci Res (TNO) 2003; 148:1-89.

24. Augner C, Hacker GW, Oberfeld G, et al. Effects of exposure to GSM mobile phone base station signals on salivary cortisol, alpha-amylase, and immunoglobulin A. Biomed Environ Sci 2010;23:199-207.

25. Eger H, Jahn M. Spezifische Symptome und Mobilfunkstrahlung in Selbitz (Bayern) Evidenz für eine Dosiswirkungsbeziehung. Umwelt Medizin Gesellschaft 2010;2:130-9.

26. Danker-Hopfe H, Dorn H, Bornkessel C, et al. Do mobile phone base stations affect sleep of residents? Results from an experimental double-blind sham-controlled field study. Am J Hum Biol 2010;5:613-18.

27. Bortkiewicz A, Gadzicka E, Szyjkowska A, et al. Subjective complaints of people living near mobile phone base stations in Poland. Int J Occup Med Environ Health 2012;25:31-40.
28. Eskander EF, Estefan SF, Abd-Rabou AA. How does long term exposure to base stations and mobile phones affect human hormone profiles? Clin Biochem 2012;45:157-61.

29. Shahbazi-Gahrouei D, Karbalae M, Moradi HA, et al. Health effects of living near mobile phone base transceiver station (BTS) antennae: a report from Isfahan, Iran. Electromagn Biol Med 19 Jun 2013. Epub ahead of print.

30. Röösli M, Frei P, Mohler E, et al. Systematic review on the health effects of exposure to radiofrequency electromagnetic fields from mobile phone base stations. Bull World Health Organ 2010;88:887-96.

31. Efron B, Tibshirani R. An introduction to the bootstrap. Boca Raton, FL: Chapman \& Hall/CRC, 1993; ISBN 0-412-04231-2. Software.

32. Maxwell SE, Delaney HD. Bivariate median-splits and spurious statistical significance. Psychol Bull 1993;113:181-90.

33. Royston P, Altman DG, Sauerbrei W. Dichotomizing continuous predictors in multiple regression: a bad idea. Stat Med 2006;25:127-41.

34. Austin PC, Brunner LJ. Inflation of the type I error rate when a continuous confounding variable is categorized in logistic regression analyses. Stat Med 2004;23:1159-78.

35. Peduzzi P, Concato J, Kemper E, et al. A simulation study of the number of events per variable in logistic regression analysis. $J$ Clin Epidemiol 1996;49:1373-9.

36. Baliatsas $\mathrm{C}$, van Kamp I, Kelfkens $\mathrm{G}$, et al. Non-specific physical symptoms in relation to actual and perceived proximity to mobile phone base stations and powerlines. BMC Public Health 2011;11:421.

37. Hutter $\mathrm{H}$, Moshammer $\mathrm{H}$, Wallner $\mathrm{P}$, et al. Public perception of risk concerning celltowers and mobile phones. Soz Präventivmed 2004;49:62-6.

38. Pall ML. Electromagnetic fields act via activation of voltage-gated calcium channels to produce beneficial or adverse effects. $J$ Cell $\mathrm{Mol}$ Med 2013;7:958-65.

39. Coggon D. Health risks from mobile phone base stations. Occup Environ Med 2006;63:298-9.

40. Real Decreto 1066/2001 Telecomunicaciones/TelefoniaMovil/ RD1066_2001.pdf http://www.mityc.es/esES/OficinaVirtual/ Documents/SE\%20

41. [No authors listed]. Guidelines for limiting exposure to time-varying electric, magnetic, and electromagnetic fields (up to $300 \mathrm{GHz}$ ). International Commission on Non-lonizing Radiation Protection Health Phys 1998;74:494-522.

42. Haumann T, Münzenberg U, Maes W, et al. HF-Radiation levels of GSM cellular phone towers in residential areas. 2nd International Workshop on Biological effects of EMFS. October 2002; Rhodes (Greece), vol 1:327-33. 